\title{
Retrospective Study on Upper Gastrointestinal Endoscopic Findings in Patients with Dyspepsia without Alarm Features in International Islamic University Malaysia Medical Centre
}

Nik Arsyad Bin Nik Muhamad Affendi ${ }^{1}$, Farhana binti Ismail ${ }^{1}$, Khairul Azhar Bin Jaafar $^{1}$, Muhammad Ateeq Bin Md Jalil ${ }^{1}$, Wan Hasrol Faes Bin Wan Abdul Jalil ${ }^{1}$, ${ }^{1}$ Department of Internal Medicine, Kulliyyah of Medicine, International Islamic University Malaysia

Presenter: Nik Arsyad Bin Nik Muhamad Affendi

Introduction: The purpose of this study was to review the significance of oesophago-gastroduodenoscopy (OGD) findings in patients with dyspepsia but without alarm features. Materials and Methods: OGD data from January 2017 to December 2017 were collected from ipesakit. The demographic details, indications and findings were reviewed. Results: OGDs were performed. Among these 56 (49\%) were performed on dyspeptic patients with no alarm features. This subgroup was further analysed. Thirty two (57\%) patients in this subgroup were female and 24 (43\%) were male. 33 (59\%) were 50 years and younger. Twenty (36\%) patients were between 51 and 70 years old, while 3 (5\%) patients were above 70 years of age. The commonest finding was gastritis $(70 \%, n=39)$, followed by $\mathrm{F} 3$ gastric ulcer (3.5\%, n=2), F3 duodenal ulcer (3.5\%, n=2), gastric fundic polyp (1.8\%, $n=1)$, and hiatus hernia $(1.8 \%, n=1) .11(20 \%)$ patients had normal finding. No malignancy or pre malignancy lesion were found in this cohort. Two patients had positive CLO test. Conclusion: OGD in patients with dyspepsia but without alarm features has low yield of significant findings. This procedure may unnecessarily expose patients to the associated potential risks and may not be cost effective. This can be addressed by introducing a hospital guideline for OGD referral. Low positivity of CLO test may also need further evaluation with regards to its sensitivity and specificity. Alternative tests for $\mathrm{H}$ Pylori detection such as stool antigen test or urea breath test may need to be adopted. 